\title{
MORFOLOGI Bruguiera cylindrica (L.) Blume YANG TUMBUH DI HUTAN MANGROVE KECAMATAN SIBERUT UTARA KABUPATEN KEPULAUAN MENTAWAI
}

\author{
Rizki, Elza Safitri, Asroen \\ Program Studi Pendidikan Biologi STKIP PGRI Sumatera Barat. \\ Jl Gunung Pangilun Padang Sumatera Barat. \\ Email.khi_bio@yahoo.com
}

\begin{abstract}
Morphology is the result of expression of a genotype that is influenced by environmental factors. Plant morphological variations may occur due to the different conditions of the region, these conditions may include differences in geographical location, ecological conditions such as variations in temperature, humidity, nutrition and others. Has done research on the morphology of Bruguiera cylindrica (L.) Blume grown in mangrove forest districts North Siberut Mentawai District. This morphological study aims to determine the morphology B. Cylindrica and compare it with the data that has been there before. This study was conducted in May-June 2015 in the mangrove forest District of North Siberut Mentawai District. The research method used in the study was a survey and a collection directly in the field. Samples contained area of mangrove forests are taken at random and then proceed to describe the morphology of the species B. Cylindica structure. Based on the research that has been dilakkan B. cylindrica can diketahuhi there are some differences in morphological characters on the roots of these species such as shape, color roots, tree height, color of trunks and branches, filotaksis leaves, leaf color, leaf length, flower color, fruit color, length and the diameter hipokotil. Then from this study can also be added some new information that has not been previously reported.
\end{abstract}

Key word: morfologi Bruguiera cylindrica (L.) Blume, mangrove, mentawai

\section{PENDAHULUAN}

Mangrove merupakan suatu ekosistem yang komplek baik untuk tumbuhan maupun komunitasnya. Mangrove Juga di istilahkan untuk pohon yang hidup di daerah berlumpur, basah dan terletak di perairan pasang surut daerah tropis. Selain itu mangrove juga suatu vegetasi hutan yang tumbuh di antara garis pasang surut sehingga juga di sebut hutan pasang. Istilah-istilah mangrove baik digunakan untuk individu species tumbuhan maupun untuk komunitas pada habitat mangrove (Indryanto, 2006). Tumbuhan pada ekosistem ini merupakan tempat hidup berbagai jenis invertebrata dan vertebrata yang membentuk suatu kesatuan sistem yang menyusun suatu hutan
Vegetasi yang terdapat dalam ekosistem hutan mangrove umumnya didominasi oleh tumbuhan yang mempunyai pneumatofora, atau yang dikenal juga dengan akar nafas, dimana akan mendapat oksigen dalam lumpur yang anoksit, daun-daunnya kuat mengandung banyak air dan mempunyai jaringan internal penyimpan air. Vegetasi utama penyusun hutan mangrove memeiliki habitus tumbuhan dapat berupa pohon atau semak, di bagian bawah batangnya mempunyai akar tunjang dan pada ujung setiap akarnya terdapat akar yang banyak menyamping sehingga mangrove ini tertanam kuat dalam lumpur. Tumbuhan ini bersifat vivipar (buah yang sudah berkecambah diatas pohon). Akar lembaga yang panjang dihasilkan oleh buah yang sudah berkecambah di atas pohon sebelum kecambahnya jatuh ke dalam air. Akar lembaga itu cukup ringan sehingga 
buah tetap bisa terapung, kecambah itu kemudian hanyut di bawa arus sungai atau laut hingga sampai ketepi dan tertanam ke dalam lumpur seperti pada tumbuhan Rhizophora, Ceriop dan Bruguiera (Ewuse, 1990). Asriyana dan Yuliana (2012), menuliskan bahwa tumbuhan yang dijumpai pada ekosistem hutan mangrove ini terdiri atas 12 genus tumbuhan berbunga antara lain Rhizophora, Avicennia, Sonneratia, Bruguiera, Ceriop, Xylocarpus, Lumnitzera, Languncularia, Aigiceras, Aegiatilis, Snaeda, dan Sconocarpus.

B. cylindria $(\mathrm{L}$.) Blume merupakan salah satu familia Rhizoporaceae yang menusun hutan mangrove, tumbuhan ini sering juga disebut burus, tanjang, tanjang putih, tanjang sukim, tanjang sukun. Perawakan berupa Pohon mencapai $23 \mathrm{~m}$ berakar lutut dan akar papan yang melebar ke samping di bagian pangkal pohon, Kulit kayu abu-abu, relatif halus dan memiliki sejumlah lentisel kecil, Noor dkk (2006). Daun berwarna hijau cerah bagian bawahnya hijau agak kekuningan. Letak daun sederhana dan berlawanan. Bentuk elips, ujung agak meruncing, ukuran 7-17 berukuran 2-8 $\mathrm{cm}$, Sudarmiji (2004). Bunga mengelompok 3, letaknya di ujung atau ketiak tangkai/tandan bunga. Mahkota berwarna putih, kelopak bunga berjumlah 8 berwarna hijau kekuningan, berukuran 3-4 mm bawahnya seperti tabung. Hipokotil berbentuk silindris memanjang, sering juga berbentuk kurva berukuran panjang 8- $15 \mathrm{~cm}$ dan berdiameter 5- $10 \mathrm{~mm}$ berwarna hijau. Pangkal buah menempel pada kelopak bunga, (Rosadi, 2013).

Tumbuhan $B$. cylindirica ini dapat ditemukan di daerah pantai yang berlumpur berpasir di daerah kepulauan Mentawai, satu diantaranya daerah kepulauan Siberut bagian Utara. Secara geografis Kepulauan Mentawai ini khususnya pulau Siberut merupakan rangkaian gugusan kepulauan yang membujur dari Utara ke Selatan. Bagian Timur berbentuk landai, mudah dicapai dari Pulau Sumatera. Pada bagian pinggir pantai terdapat teluk-teluk yang tanjung. Sebaran mangrove di Kabupaten kepulauan Mentawai berkaitan dengan adanya beberapa sungai kecil yang mengalir ke laut, serta didukung adanya bentuk morfologi pantai yang berupa teluk-teluk kecil. Sementara itu, sifat pantai di Mentawai yang cenderung berlumpur (Anggriawan, 2011).
Letak geografis Mentawai memungkinkan munculnya variasi pada species tumbuhan yang hidup di wilayah tersebut. Perbedaan daerah tumbuh suatu species dapat menjadikan species tersebut memiliki karakter tersendiri. beberapa diantaranya menjadi ecotype. Fenotipe yang terlihat melalui ekspresi morfologi merupakan hasil kolaborasi antara genotoipe dan pengaruh lingkungan. Hasil ekspresi ini dapat menghasilkan suatu variasi baru yang dapat berbeda pada masing-masing daerah, apalagi tempat hidupnya suatu tumbuhan tersebut memiliki karakteristik tertentu, begitu juga dengan B. cylindrica di Siberut Utara ini. Karakteristik kepulauan yang terletak jauh dari pulau sumatera memungkinkan tumbuhan ini memiliki karakter yang berbeda dari karakter yang telah di publikasi sebelumnya.

\section{BAHAN DAN METODE}

Penelitian ini telah dilaksanakan pada bulan Mei-Juni 2015 pengambilan sampel dilakukan di daerah hutan mangrove Kecamatan Siberut Utara Kabupaten Kepulauan Mentawai. Pengamatan struktur morfologi species $B$. cylindica dilakukan di laboratorium Botani Pendidikan Biologi STKIP PGRI Sumatera Barat.

Alat yang akan digunakan dalam penelitian ini adalah, kamera digital, parang, meteran, gunting tanaman, triplek, jarum jahit, kapter, oven, alat ukur mm, serta alat tulis dan buku identifikasi. sedangkan Bahan yang digunakan adalah kertas koran, kantong specimen/karong, lebel specimen, lakban, roll, kertas kalkil, mounting, tali rafia, benang jagung, alkohol $96 \%$, plastik ukuran $50 \mathrm{~kg}$ dan tumbuhan $B$. cylindica yang dijadikan spesimen

Metode penelitian yang digunakan dalam penelitian adalah survey dan koleksi langsung dilapangan. Sampel yang terdapat dikawasan hutan mangrove diambil secara acak dan kemudian dilanjutkan mendiskripsikan struktur morfologi species $B$. cylindica

\section{Cara kerja \\ Di Lapangan}

Sebelum dilakukan pengambilan bahan koleksi, terlebih dahulu dilakukan penentuan jalur lokasi penelitian dengan jumlah 3 jalur lokasi, penentuan jalur lokasi ini dibuat secara 
vertikal pantai berdasarkan perbedaan zonasi dan kondisi daerah mangrove. Pada setiap jalur yang ditentukan dimbil sebanyak 3 sampel secara acak. Hal ini bertujuan sebagai pembanding karakteristik species $B$. cylindica. Sebelum pengambilan sampel dilapangan dilakukan pengamatan seperti pencatatan karakter tumbuhan $B$. cylindica yang meliputi habitat, habitus, dan warna.

Setelah pengamatan dilakukan dilanjutkan dengan pengoleksian tumbuhan. Sampel diambil sebanyak 3 rangkap (kecuali Akar) diberi label lapangan yang diberi nomor koleksi. Setiap koleksi dimasukkan kedalam lipatan koran, sampel ditumpuk dan diikat dengan menggunakan tali rafia. Kemudian disiram dengan menggunakan alkohol $96 \%$ sampai basah lalu disimpan di dalam kantong plastik yang tidak bocor berukuran $50 \mathrm{~kg}$ setelah itu dilakban dan dilapisi dengan trilplek berukuran $40 \times 30 \mathrm{~cm}$ kemudian diikat kuat dengan menggunakan tali rafia. Pengeringan specimen di lakukan dengan cara manual yaitu dengan panas sinar matahari.

\section{Di laboratorium}

1. Pembuatan herbarium

Sampel yang telah benar-benar kering dijahitkan di atas kertas mounting dengan ukuran 30 x $40 \mathrm{~cm}$, kemudian diberi label herbarium setelah itu herbarium tersebut difotocopy dan digambarkan pada kertas kalkir.

2. Penentuan dan Pengukuran Karakter Morfologi

Untuk mengetahui karakter morfologi suatu tumbuhan dilakukan pengamatan dan pengukuran terhadap karakter morfologi tumbuhan yang meliputi, akar, batang, daun, buah dan bunga. Pengamatan dan pengukuran pada akar meliputi: bentuk, tinggi, diameter, permukaan dan warna. Batang meliputi: warna (batang utama, cabang tua,cabang muda) begetah/tidak, warna getah, arah tumbuh, arsitektur, tipe permukaan, percabangan, tinggi, diameter dan karakter lain. Daun meliputi: warna daun mudah, pucuk, dan tua (warna tangkai, tepi, pangkal ujung) filotaksis, kelengkapan, bentuk umum, pangkal, tepi dan ujung daun, pertulangan daun, permukaan atas bawah lebar dan panjang daun, bergetah/tidak, bentuk, panjang, permukaan atas bawah dan kedudukan. Buah meliputi tipe, warna, tnggal/majemuk bergetah/tidak. Bunga meliputi letak, macam, tipe bunga, kelengkapan bunga.

3. Identifikasi sampel

Kegiatan identifikasi ini dilakukan seperti, Mencocokan contoh tumbuhan yang dibawah dari lapangan dengan contoh spesimen tumbuhan yang ada diruang koleksi, Mencocokan atau menyamakan tumbuhan yang dibawa dari lapangan dengan gambar tumbuhan yang telah di publikasi atau diterbitkan. Memperoleh informasi nama tumbuhan yang tepat melalui orang yang berpengalaman dan telah menguasai identifikasi tumbuhan. penentuan karakter morfologi ini menggunakan buku: Lawrence (1964) Giesen (2007), Yudianto (1992), Tjitrosoepomo (2003), Noor dkk (2006).

\section{Analisis data}

Data yang telah didapatkan dari hasil observasi di lapangan dideskriptif melalui studi kepustakaan dituliskan dalam bentuk tabel dimana pada tabel ini akan dicantumkan karakter morfologi tumbuhan $B$. cylindica yang meliputi akar ,batang, daun, buah dan bunga yang telah ditentukan. Kemudian hasildeskripsi variasi morfologi $B$. cylindica yang didapat dari penelitaian dibandingkan dengan informasi yang telah ada sebelumnya

\section{HASIL DAN PEMBAHASAN}

Hasil pengamatan dituliskan di Tabel 1 . B. cylindria (L.) Blume memiliki tipe akar lutut yang melebar dibagian pangkal batang dengan warna akar coklat tua, kecoklatan berbintik kuning; warna batang utama putih keabu-abuan; warna cabang tua kecoklatan; percabangan monopodial; tinggi 13,5-17,0 m; diameter 4,20$13,37 \mathrm{~cm}$; bentuk umum daun elips bulat telur; ukuran daun tua 5 - $9 \times 3,3-4,3 \mathrm{~cm}$; ukuran daun muda6,1- 7,2 x 2,3- 4,4 cm; panjang tangkai tua 1,7-3,6 cm; panjang tangkai muda1,7- 2,1 cm; bunga mengelompok 2-3 kelompok bunga; jumlah sepal 8 warna hijau kekuningan; jumlah petal 8 dengan warna kuning pucat putih; buah berbentuk tabung melingkar warna kecoklatan; warna hipokotil hijau muda keunguan dengan panjang 3-7,5 cm diameter 05- 0,8 mm. Menurut Gissen (2007), Sudarmiji (2004), dan Sutarno (2002), species 
tumbuhan ini memiliki ketinggian pohon 4-23 $m$ dengan warna batang abu-abu, daun berbentuk elips bulat panjang dengan ukuran panjang 8-10 x 2-8 cm. Hipokotil berwarna hijau keunguan berbentuk silindris memanjang dengan ukuran panjang $8-15 \mathrm{~cm}$, berdiameter 5$10 \mathrm{~mm}$. Species tumbuhan ini ditemukan pada daerah dengan kondisi tanah berpasir bercampur tanah liat dan sedikit berlumpur. Kemampuan tumbuhnya pada kondisi tanah berpasir dan tanah liat membuat jenis pohon ini memiliki perbedaan karakter morfologi. Adanya perbedaan karakter morfologi ini menurut Noor dkk (2006), Onrizal (2012), mengatakan bahwa species tumbuhan ini pertumbuhannya lambat dan sangat bergantung kepada akar napas untuk memperoleh pasokan oksigen yang cukup, oleh sebab itu sangat responsip terhadap pergenagan pasang yang berkepanjangan. Jenis tumbuhan ini memiliki hipokotil yang ringan dan mengapung sehingga penyebarannya dapat dibantu oleh arus air.

Tabel 1 Karakter Morfologi B. cylindica di Hutan Mangrove Kecamatan Siberut Utara Kabupaten Kepulauan Mentawaidan Perbandingan Data dengan Informasi Sebelum Penelitian

\begin{tabular}{|c|c|c|c|}
\hline No & Karakter Morfologi & B cylindrica (L.) Blume & Sumber bacaan* \\
\hline 1 & Akar & & \\
\hline \multirow[t]{5}{*}{ (1) } & (2) & (3) & (4) \\
\hline & Bentuk akar & $\begin{array}{l}\text { Lutut, melebar umunya } \\
\text { meyebar dibagian pangkal } \\
\text { batang (terspesialisasi) }\end{array}$ & Lutut melebar kesamping $^{3}$ \\
\hline & Warna akar & $\begin{array}{l}\text { Kecoklatan, coklat tua } \\
\text { berbintik kuning }\end{array}$ & Coklat hingga coklat abu-abu ${ }^{1}$ \\
\hline & Bergetah/tidak & Bergetah & - \\
\hline & Warna getah & Bening & - \\
\hline \multirow[t]{16}{*}{2} & Batang & & \\
\hline & Bentuk batang utama & Bulat (teres) & - \\
\hline & Bentuk cabang muda & Bulat (teres) & - \\
\hline & Bentuk cabang tua & Bulat (teres) & - \\
\hline & Percabangan & Monopodial & Monopodial $^{4}$ \\
\hline & Permukaan & Halus hingga kasar & $\begin{array}{l}\text { Halus dan memiliki lenti sel } \\
\text { kecil }^{1}\end{array}$ \\
\hline & Arah tumbuh & Tegak lurus (erectus) & - \\
\hline & Bergetah/tidak & Bergetah & - \\
\hline & Tinggi & $13,5-17,0 \mathrm{~m}$ & $4^{2}-23^{1} \mathrm{~m}$ \\
\hline & Diameter & $4,20-13,37 \mathrm{~cm}$ & - \\
\hline & Warna batang utama & Putih keabu-abuan, & $\mathrm{Abu}-\mathrm{abu}^{3}$ \\
\hline & Warna cabang muda & Abu-abu kecoklatan & - \\
\hline & Warna cabang tua & Kecoklatan & Coklat $^{3}$ \\
\hline & Warna ruas & Abu-abu, keputih-putihan & Coklat keabu-abuan ${ }^{1}$ \\
\hline & Warna buku & Kecoklatan & Coklat muda ${ }^{2}$ \\
\hline & Karakter lain & Batang Berbintik kuning & - \\
\hline
\end{tabular}

*Sumber: Gissen ${ }^{1}$ (2007), Sudarmadji ${ }^{2}$ (2004), Noor dkk ${ }^{3}$ (2006),Sutarno ${ }^{4}$ (2002). 
Lanjutan Tabel 1..

\begin{tabular}{|c|c|c|c|}
\hline (1) & (2) & (3) & (4) \\
\hline \multirow[t]{31}{*}{3} & Daun & & \\
\hline & Bentuk umum daun & Elips bulat telur & Elips bulat panjang $^{1}$ \\
\hline & Kelengkapan daun & Tidak lengkap & Tidak lengkap $^{1}$ \\
\hline & Macam/ filotaksis & Berhadapan & Sederhana dan berlawanan ${ }^{3}$ \\
\hline & Bentuk pangkal daun & $\begin{array}{l}\text { Meruncing } \\
\text { (acuminatus) }\end{array}$ & - \\
\hline & Bentuk tepi daun & Rata (intiger) & - \\
\hline & Bentuk ujung daun & Meruncing (acuminatus) & Meruncing (acuminatus) ${ }^{2}$ \\
\hline & Pertulanagan daun & Menyirip (penninervis) & - \\
\hline & Tipe daun & Tunggal & Tunggal $^{2}$ \\
\hline & Bergetah/tidak & Bergetah & - \\
\hline & Warna pucuk & Hijau pudar & - \\
\hline & Warna daun tua & $\begin{array}{l}\text { Hijau pekat, hijau } \\
\text { kekuningan }\end{array}$ & Hijau muda ${ }^{3}$, Hijau cerah ${ }^{1}$ \\
\hline & Warna permukaan atas & $\begin{array}{l}\text { Hijau pudar, hijau } \\
\text { kekuningan }\end{array}$ & Hijau cerah $^{2}$ \\
\hline & Wrna permukaan bawah & Hijau pudar kekuningan & Hijau agak kekuningan ${ }^{4}$ \\
\hline & Warna tangkai tua & Hijau pudar & - \\
\hline & $\begin{array}{l}\text { Warna permukaan atas } \\
\text { tangkai tua }\end{array}$ & Hijau pudar kekuningan & - \\
\hline & $\begin{array}{l}\text { Warna permukaan bawah } \\
\text { tangkai tua }\end{array}$ & Hijau kekuningan & - \\
\hline & Panjang daun tua & $5-9 \mathrm{~cm}$ & $8^{1}-10^{3} \mathrm{~cm}$ \\
\hline & Lebar daun tua & $3,3-4,3 \mathrm{~cm}$ & $2^{2}-8 \mathrm{~cm}$ \\
\hline & Panjang tangkai tua & $1,7-3,6 \mathrm{~cm}$ & $3-4,5 \mathrm{~cm}$ \\
\hline & Diameter tangkai & $0,2-0,4 \mathrm{~cm}$ & - \\
\hline & Warna daun muda & Hijau Kekuningan & - \\
\hline & $\begin{array}{l}\text { Warna permukaan atas daun } \\
\text { muda }\end{array}$ & Hijau kekuningan & - \\
\hline & $\begin{array}{l}\text { Warna permukaan bawah } \\
\text { daun muda }\end{array}$ & Hijau pudar & Hijau-hijau tua ${ }^{1}$ \\
\hline & Warna tangkai muda & Kuning pucat, kuning pudar & Kuning $^{2}$ \\
\hline & $\begin{array}{l}\text { Warna permukaan atas } \\
\text { tangkai muda }\end{array}$ & Kuning kehijauan & Hijau pudar ${ }^{4}$ \\
\hline & $\begin{array}{l}\text { Warna permukaan bawah } \\
\text { tangkai muda }\end{array}$ & Kuning pucat kehijauan & \\
\hline & Panjang daun muda & $6,1-7,2 \mathrm{~cm}$ & - \\
\hline & Lebar daun muda & $2,3-4,4 \mathrm{~cm}$ & - \\
\hline & Panjang tangkai muda & $1,7-2,1 \mathrm{~cm}$ & - \\
\hline & Diameter tangkai & $0,2-0,3 \mathrm{~mm}$ & - \\
\hline \multirow[t]{12}{*}{4} & Bunga & & \\
\hline & Macam & Berkelompok 2-3 per tandan & $\begin{array}{l}\text { Berkelompok 2-3 terletak } \\
\text { ketiak daun }\end{array}$ \\
\hline & Letak & Axillary & Axillary ${ }^{1}$ \\
\hline & Kelopak (kalix) & & \\
\hline & Bentuk & Bintang membalik & - \\
\hline & Warna permukaan atas & Hijau kekuningan & \\
\hline & Warna pemukaan bawah & Hijau pucat, kehijauan & - \\
\hline & Jumlah sepal & 8 sepal & 8 sepal $^{2}$ \\
\hline & Mahkota (corolla) & & \\
\hline & Bentuk & Bintang & - \\
\hline & Warna & Kuning pucat, putih & Putih $^{4}$ \\
\hline & Jumlah petal & 8 petal & 8 petal $^{1}$ \\
\hline
\end{tabular}


Lanjutan Tabel $1 .$.

\begin{tabular}{clll}
\hline \multicolumn{1}{c}{$(2)$} & \multicolumn{1}{c}{$(3)$} & \multicolumn{1}{c}{$(4)$} \\
\hline 5 & Buah & & - \\
& Bentuk & Bulat panjang & \\
& Warna & Hijau pudar & Hijau, hijau keunguan $^{1}$ \\
& Diameter & $0,5-0,7 \mathrm{~mm}$ & $0,5^{3}-1,0^{1} \mathrm{~cm}$ \\
Bergetah/tidak & Bergetah & - \\
Warna getah & Bening & - \\
Tunggal/majemuk & Tunggal & - \\
Permukaan & Halus & - \\
Warna hipokotil & Hijau muda, keunguan & Hijau $^{1}$, keunguan $^{3}$ \\
Bentuk hipokotil & Silindris & silindris memanjang $^{3}$ \\
Panjang hipokotil & $3-7,5 \mathrm{~cm}$ & $8^{2}-15^{3} \mathrm{~cm}$ \\
& Diameter hipokotil & $0,5-0,8 \mathrm{~cm}$ & $5^{4}-10^{1} \mathrm{~cm}$ \\
\hline
\end{tabular}

* Sumber: Gissen ${ }^{1}$ (2007), Sudarmadji² (2004), Noor dkk ${ }^{3}$ (2006),Sutarno ${ }^{4}$ (2002).

Perbedaan beberapa karakter morfologi diperkirakan karena perbedaan lokasi dan kondisi tempat tumbuh B. Cylindrica ini. Perbedaan ini dapat dilihat dari tinggi batang, dari informasi yang diperoleh tinggi batang tumbuhan ini 4-23 m (Giesen, 2007) (Sudarmaji, 2004), namun di lokasi penelitian tinggi batang tidak sampai $23 \mathrm{~m}$, yaitu $13,5 \mathrm{~m}$ sampai dengan $17 \mathrm{~m}$. selain tinggi batang, warna daun juga ada perbedaan dengan informasi yang didapatkan. Warna daun tumbuhan di lokasi penelitian hijaunya lebih pekat. Panjang hipokotil 3-7,5 cm dan diameter $0,5-0,8 \mathrm{~cm}$ sedangkan dari informasi sebelumnya panjang hipokotil dari $B$. Cylindrica ini adalah 8-15 cm dan diameternya 5-10 cm Gissen ${ }^{1}$ (2007), Sudarmadji ${ }^{2}$ (2004), Noor dkk ${ }^{3}$ (2006), Sutarno ${ }^{4}$ (2002).

\section{KESIMPULAN}

Berdasarkan penelitian yang telah dilakkan pada $B$. cylindrica dapat diketahuhi terdapat beberapa perbedaan karakter morfologi pada species ini seperti bentuk akar, warna akar, tinggi pohon, warna batang dan cabang, filotaksis daun, warna daun, panjang daun, warna bunga, warna buah, panjang dan diameter hipokotil. Kemudian dari penelitian ini juga dapat ditambahkan beberapa informasi baru yang belum dilaporkan sebelumnya.

\section{UCAPAN TERIMA KASIH}

Terima kasih penulis ucapkan kepada Irma Leilani, M.Si., Dra. Des M., M.S., Rina Widiana, M.Si dan Siska Nerita, M.Pd.

\section{DAFTAR KEPUSTAKAAN}

Anggriawan, R. 2011. Alam Kita Taman Nasional Siberut. (Online). Html: diakses pada tanggal 22 februari 2015

Ardhana dan Darmadi. 2010. Komposisi JenisJenis Tumbuhan Mangrove Di Kawasan Hutan Perapat Benoa Desa Pemogan, Kecamatan Denpasar Selatan, Kodya Denpasar, Propinsi Bali.Jurnal ILMU DASAR, Vol. 11 No. 2, Juli 2010: 167171: Jurusan Biologi FMIPA Universitas Udayana Bali.

Catherin. 1993. Field guide to the mangroves of quesland. Australian: institute of marine science.

Ewusie, J. Yanney. 1990. Pengantar Ekologi Tropika. Bandung: ITB

Giessen. W, S. Wulffraat, M. Zieren, and L. Scholten. 2007. Mangrove Guidebook For Southeast Asia. FAO and Wetland International: Thailand.

Indryanto. 2006. Ekologi Hutan. Jakarta: PT Bumi Aksara.

Kordi, K., M. Ghufan. 2011. Budi Daya 22 Komoditas Laut Untuk Konsumsi Lokal Dan Ekspor. Yokyakarta: ANDI 
Kordi, K., M. Ghufran.2012. Ekosistem Mangrove Potensi, Fungsi dan Pengelolaannya. Jakarta: Rineka Cipta.

Lawrence, G. H. M. 1968. Taxonomy of Vascular Plants. The Mc millan Company, New York

Melana, D.M., J. Atchue III, C.E. Yao, R. Edwards, E.E. Melana and H.I. Gonzales. 2000. Mangrove Management Handbook. Department of Environment and Natural Resources, Manila, Philippines through the Coastal Resource Management Project, Cebu City, Philippines.

Mina, M. 2008. Fied guide to maldivian mangroves. LIVE and LEARN environmental education. UNICEF.

Noor Y. R, M. Khazali, dan I. N. N. Suryadiputra. 2006. Panduan Pengenalan Mangrove Di Indonesia. Institut Pertanian Bogor.

Nontji, Anugerah.1993. Laut Nusantara. Jakarta: Djambatan.

Nybakken, W.James. 1988. Biologi Laut Suatu Pendekatan Ekologis. Jakarta: PT Gramedia.

Onrizal. 2008. Panduan Pengenalan Dan Analisis Vegetasi Hutan Mangrove. Departemen Kehutanan, Fakultas Pertanian: Universitas Sumatera Utara.

Onrizal. 2012. Pengenalan Jenis Mangrove. Medan: the mangrove reasearh institute.
Rosadi, A., Sahad, M., Budi, I. 2013. Karakterisasi Dan Kekerabatan Tumbuhan Mangrove Rhizophoraceae Berdasarkan Morfologi, Anatomi Dan Struktur Luar Serbuk Sari.Jurusan Biologi FMIPA UNPAD: PTNBR BATAN Bandung Sumedang.

Sutarno. A, D. Setyawan. A. Susilowati. 2002. Biodiversitas Genetik, Species, Dan Ekosistem Mangrove Di Jawa. Surakarta: Jurusan Biologi Fakultas Matematika Dan Ilmu Penegetahuan Alam Universitas Sebelas Maret.

Sudarmadji. 2004. Deskripsi Jenis-jenis Anggota Suku Rhizophoraceae di Hutan

Tjitrosoepomo, G. 2003. Morfologi Tumbuhan. Yokyakarta: Gadjah Mada Universisy Press.

Mangrove Taman Nasional Baluran Jawa Timur. Journal Biodiversitas.Jurusan Biologi FMIPA Universitas Jember.

Suryono, A. 2013. Sukses Usaha Pembibitan Mangrove Sang Penyelamat Pulau. Banguntapan, Bantul, Yokyakarta: Pustaka Baru Press.

Yudianto, A. Suroso. 1989. Mengerti Morfologi Tumbuhan (Apa Dan Mengapa). Bandung: TARSITO.

Yuliana dan Asryanan. 2012. Produktivitas Perairan. Jakarta: PT Bumi Aksara. 